\title{
ARTICULATE STORYLINE SEBAGAI MEDIA PEMBELAJARAN INTERAKTIF UNTUK PESERTA DIDIK MADRASAH IBTIDAIYAH
}

\section{ARTICULATE STORYLINE AS INTERACTIVE LEARNING MEDIA FOR MADRASAH IBTIDAIYAH STUDENTS}

\author{
Juhaeni $^{1}$, Safaruddin ${ }^{2}$, Zuha Prisma Salsabila ${ }^{3}$ \\ ${ }^{1,3}$ Pendidikan Guru Madrasah Ibtidaiyah UIN Sunan Ampel Surabaya, \\ ${ }^{2}$ Pendidikan Agama Islam IAIM Sinjai \\ 1,3Jl. Ahmad Yani No. 117, Kota Surabaya, Jawa Timur 60237, ${ }^{2} J 1$. Sultan Hasanudin No. 20, \\ Balangnipa, Kabupaten Sinjai, Sulawesi Selatan 92614 \\ Email: juhaeni@uinsby.ac.id ${ }^{1}, \underline{\text { sarthi339@ gmail.com }}^{2}, \underline{\text { zuha.prisma@ gmail.com }}^{3}$
}

Submitted: 03-08-2021, Revised: 03-11-2021, Accepted: 15-11-2021

\begin{abstract}
Abstrak
Penelitian ini didasari framework Technological Pedagogical Content Knowledge (TPACK) yakni kerangka kerja untuk memberikan pemecahan masalah terkait integrasi Teknologi Informasi dan Komunikasi (TIK) yang berfokus pada pemanfaatan articulate storyline sebagai media pembelajaran interaktif untuk Madrasah Ibtidaiyah (MI). Tujuan penelitian ini adalah menjabarkan definisi, tampilan, keunggulan, dan kelemahan serta pemanfaatan articulate storyline sebagai media pembelajaran interaktif. Jenis penelitian yang digunakan yakni deskriptif kualitatif jenis studi literatur. Prosedur pengumpulan data dilakukan melalui studi dokumen, buku, dan artikel yang berkaitan dengan penelitian ini. Metode analisis data yang digunakan adalah dengan mencari, mengumpulkan, mengkaji, membandingkan, merangkum, dan menyusun sumber data yang relevan. Hasil dari penelitian ini mendeskripsikan bahwa Articulate Storyline merupakan perangkat lunak dengan fitur dan fungsi mirip microsoft powerpoint dan menggunakan sistem e-learning. Perangkat lunak ini memiliki fitur tambahan berupa icon animasi, button, dan graded question yang memudahkan pengguna dalam membuat desain media pembelajaran yang menarik dan interaktif. Akan tetapi, articulate storyline memiliki batasan dalam pembuatan slide agar bisa di akses secara mudah melalui output website. Dengan demikian, guru dapat menggunakan articulate storyline dalam merancang media pembelajaran interaktif dan meningkatkan motivasi dan aktivitas belajar peserta didik MI.
\end{abstract}

Kata Kunci: Articulate Storyline, Media Pembelajaran Interaktif, Peserta Didik

\section{Abstract}

This research is based on the Technological Pedagogical Content Knowledge (TPACK) framework, which is a framework for providing solutions to problems related to the integration of Information and Communication Technology (ICT), which focuses on the use of articulate storyline as an interactive learning medium for Madrasah Ibtidaiyah (MI). This research aims to describe the definition, display, advantages, disadvantages, and the use of articulate storyline as an interactive learning media. The research type used was the descriptive qualitative with literature study. The data collection procedure was through study documents, books, and articles related to this research. The data analysis method used was searching, collecting, reviewing, comparing, summarizing, and compiling relevant data sources. The results indicated that articulate storyline was software with features and functions similar to microsoft powerpoint and used e-learning. Additional features in animated icons, buttons, and graded questions made it easier for users to design interesting and interactive learning media. However, articulate storyline had limitations in making slides to be accessed easily through the website output. Thus, teachers can use articulate storyline in designing interactive learning media and increase motivation and learning activities of MI students. 
Keywords: Articulate Storyline, Interactive Learning Media, Students

How to Cite: Juhaeni, Safaruddin, \& Salsabila, Z. P. (2021). Articulate Storyline sebagai Media Pembelajaran Interaktif untuk Peserta Didik Madrasah Ibtidaiyah. AULADUNA: Jurnal Pendidikan Dasar Islam, 8(2), 150-159.

\section{Pendahuluan}

Teknologi merupakan alat yang dilahirkan dari suatu kebudayaan. Adanya teknologi ditujukan agar memudahkan setiap kegiatan yang dilakukan manusia. Dari zaman ke zaman, teknologi ini mengalami perkembangan dalam segala aspek baik aspek ekonomi, sosial, maupun pendidikan. Perkembangan teknologi yang pesat dalam bidang pendidikan menjadikan sebuah tantangan bagi peserta didik dan guru, karena mereka akan bersaing dalam mengejar perkembangan yang ada. Hal ini menyebabkan guru sebagai tenaga pendidik memiliki peran yang cukup signifikan sebab diperlukan upaya yang terstruktur untuk mencetak peserta didik yang unggul dan berdaya saing tinggi (Arwanda, Irianto, \& Andriani, 2020: 194).

Pergeseran sistem pendidikan dari konvensional menjadi pemanfaatan teknologi yang ada mengharuskan guru untuk berinovasi dalam proses pembelajaran. Dibutuhkan langkah yang tepat untuk menambah pemahaman peserta didik. Pemahaman ini akan berpengaruh kepada kualitas pendidikan. Salah satu langkah yang dapat dilakukan adalah dengan meningkatkan kualitas guru dalam hal memilih media pembelajaran yang tepat. Sebagai agen perubahan, guru benar-benar harus mengikuti dinamika perkembangan zaman termasuk perkembangan media pembelajaran (Darnawati, Jamiludin, Batia, Irawaty, \& Salim, 2019: 8). Media pembelajaran adalah wadah yang mengandung materi yang akan disampaikan kepada peserta didik untuk mendukung tercapainya tujuan pembelajaran (Bulan \& Wahyudi, 2021; Hadza, Sesrita, \& Suherman, 2020: 81; Juhaeni, Safaruddin, Nurhayati, \& Tanzila, 2020). Media pembelajaran yang efektif dapat menjadi cara jitu untuk mendukung pemahaman peserta didik.

Namun, tidak sedikit guru yang belum memahami pemilihan media pembelajaran yang efektif dan cocok di era digital seperti ini sebagai sarana pendukung proses belajar peserta didik (Leztiyani, 2021: 25). Media pembelajaran yang tepat digunakan pada era digitalisasi saat ini adalah multimedia interaktif dengan memanfaatkan komputer dan jaringan internet. Multimedia interaktif merupakan gabungan dari media pembelajaran visual, audio, dan audio visual yang menggunakan interaksi timbal balik antara media tersebut dengan peserta didik (Tanjung \& Parsika, 2017: 128). Multimedia interaktif memberikan pengaruh besar dalam menstimulus peserta didik, sehingga dapat memberikan respons positif terhadap materi yang telah disampaikan (Istiqlal, 2017; Safaruddin, Degeng, Setyosari, \& Murtadho, 2020).

Menurut Darnawati, Jamiludin, Batia, Irawaty, \& Salim (2019: 9), proses belajar mengajar lebih efektif apabila didukung oleh media pembelajaran visual dengan menggunakan indera pendengaran efektivitas pemahaman peserta didik mencapai $11 \%$, sedangkan dengan menggunakan indera penglihatan efektivitasnya mencapai $83 \%$. Peserta didik juga cenderung memahami sebanyak $20 \%$ dari apa yang mereka dengarkan, tetapi dapat memahami sebanyak 50\% dari apa yang mereka lihat dan dengarkan secara bersamaan.

Penerapan media pembelajaran berbasis multimedia interaktif articulate storyline dapat digunakan di segala jenjang pendidikan. Tidak terkecuali pada jenjang pendidikan Madrasah Ibtidaiyah (MI). Penggunaan software articulate storyline yang 
berisi materi berupa tulisan, video, dan kuis-kuis yang menarik diharapkan dapat membantu peserta didik yang duduk di bangku Madrasah Ibtidaiyah (MI) dalam memahami materi. Media pembelajaran ini menggunakan gawai dan internet sebagai sarana pendukung yang saat ini semua usia dan kelas pada jenjang Madrasah Ibtidaiyah (MI) dapat mengoperasikan media tersebut. Pelaksanaan dilakukan pada kelas bawah yaitu kelas satu hingga kelas tiga dinilai akan menyulitkan dan memperlambat proses pembelajaran, sehingga penerapan multimedia interaktif articulate storyline minimal dapat dilakukan pada peserta didik kelas empat (9-11 tahun). Pada usia ini, psikologi anak telah mampu mempelajari sebuah konsep, mencari sebuah hubungan pada dua hal, dan dapat menyelesaikan masalah (Trianingsih, 2016: 198), sehingga apabila diberikan media pembelajaran yang mengharuskan peserta didik untuk melakukan hubungan timbal balik mereka tidak akan kesulitan dan mempersingkat waktu proses pembelajaran.

\section{Metode Penelitian}

Penelitian ini menggunakan jenis penelitian kualitatif studi pustaka dengan teknik pengumpulan data berupa analisis dokumen didasarkan dari landasan teori, dokumen-dokumen, buku, dan artikel penelitian terdahulu dalam enam tahun terakhir (2015-2021) agar sumber data tergolong baru (Elhamid, 2019: 11). Penelitian ini mengambil studi pustaka sebagai kunci utama sumber ide dan pengolahan data, sehingga data harus dipahami, dikaji, dan diteliti agar mendapatkan data penelitian yang valid dan reliabel (Wibowo, 2021: 4). Metode analisis data pada penelitian ini menggunakan proses pencarian sumber data yang relevan, mengumpulkan sumber data, mengkaji dan membandingkan sumber data, dan meringkas dan menyusun sumber data menjadi penelitian yang baru. Subjek penelitian ini adalah dokumen, buku, website, dan artikel penelitian terdahulu yang relevan. Objek dalam penelitian ini adalah media pembelajaran interaktif dan articulate storyline (Kadir, Ningsih, Hasmiati, \& Qadrianti, 2021: 16) yang bertujuan untuk mendeskripsikan definisi, tampilan, kelebihan, dan kelemahan, serta pemanfaatan articulate storyline sebagai media pembelajaran interaktif.

\section{Hasil dan Pembahasan}

\subsection{Hasil}

\subsubsection{Pengertian Articulate Storyline}

Articulate storyline ialah sebuah software atau perangkat lunak yang berfungsi sebagai media pendukung pembelajaran. Software articulate storyline dapat digunakan dalam mempresentasikan sebuah pembelajaran, dengan berbasis e-learning software ini dapat menghadirkan sebuah storyline project yang menggabungkan semua alat media baik visual, audio, maupun audio visual, serta dapat memanfaatkan fasilitas publikasi berupa HTML5, CD, .swf, dan website (Darnawati, Jamiludin, Batia, Irawaty, \& Salim, 2019: 12).

Menurut Saski \& Sudarwanto, (2021: 1119), articulate storyline adalah perangkat lunak menggunakan sistem e-learning yang fungsinya untuk sarana pembantu pembelajaran dengan desain yang interaktif. Perangkat lunak ini diproduksi oleh perusahaan yang berjalan pada bidang e-learning yaitu perusahaan Articulate 360. Format publikasi dari articulate storyline meliputi .swf, dan .exe, sehingga mudah disimpan pada personal computer. Articulate storyline memiliki tampilan seperti 
microsoft powerpoint dan dapat dirancang secara offline, sehingga memudahkan pengguna pemula.

Articulate storyline merupakan software yang memiliki fitur hampir mirip dengan microsoft powerpoint. Articulate storyline dilengkapi lebih banyak fitur yang dapat menambah interaksi peserta didik. Slide yang dapat didesain dengan menarik dapat membantu memberikan rangsangan pemahaman kepada peserta didik (Rianto, 2020: 85).

Articulate storyline adalah produk keluaran Articulate 360 yang dikeluarkan pada tahun 2001 sebagai sarana penunjang presentasi. Software ini tidak kalah dengan multimedia interaktif lainnya. Kreativitas pengguna dalam membuat desain presentasi dengan menggabungkan seni, fitur, dan teknik yang tepat dapat menghasilkan presentasi yang menarik perhatian peserta didik. Meskipun software ini telah lama dirilis, tetapi masih banyak guru yang belum mengenali multimedia interaktif ini (Pratama, 2018: 21).

\subsubsection{Tampilan Articulate Storyline}

Fitur, icon, dan tampilan pada software articulate storyline tidak asing bagi guru atau pengguna yang terbiasa menggunakan microsoft powerpoint (Leztiyani, 2021: 30). Tampilan-tampilan yang disajikan software articulate storyline adalah sebagai berikut:

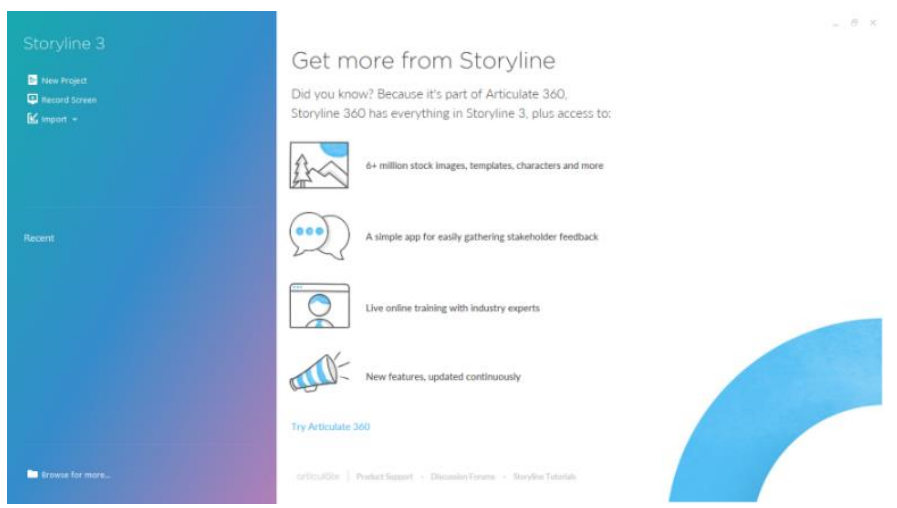

Gambar 1. Tampilan Utama Articulate Storyline

Langkah pertama untuk membuat media pembelajaran melalui articulate storyline adalah dengan membuka software dan membuat proyek baru pada bagian new project (Razilu, 2021: 19).

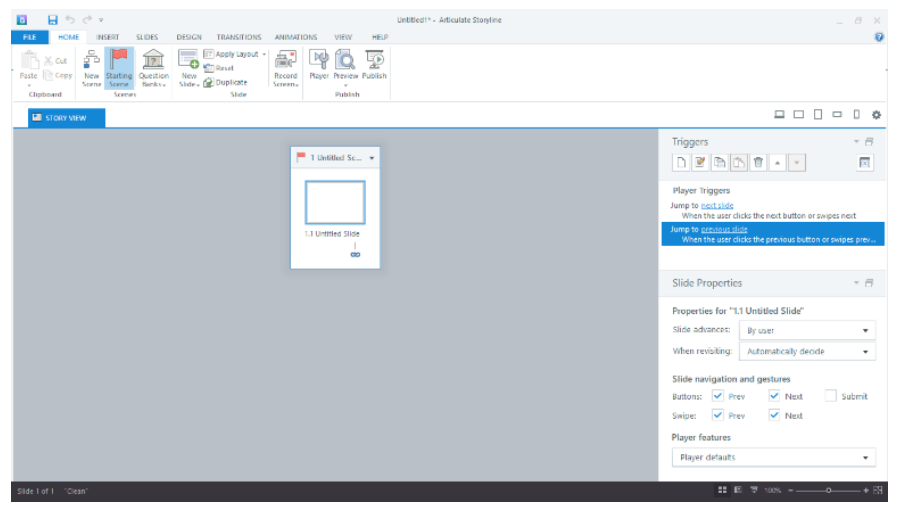

Gambar 2. Tampilan Sebelum Lembar Kerja pada Articulate Storyline 
Sebelum mulai mendesain media pembelajaran agar output yang ditampilkan akan muncul penuh oleh slide articulate storyline, maka diperlukan pengaturan pada slide properties. Pengaturan ini juga dapat disesuaikan dengan keinginan dan kebutuhan (Supriana \& Sukmana, 2018: 80).

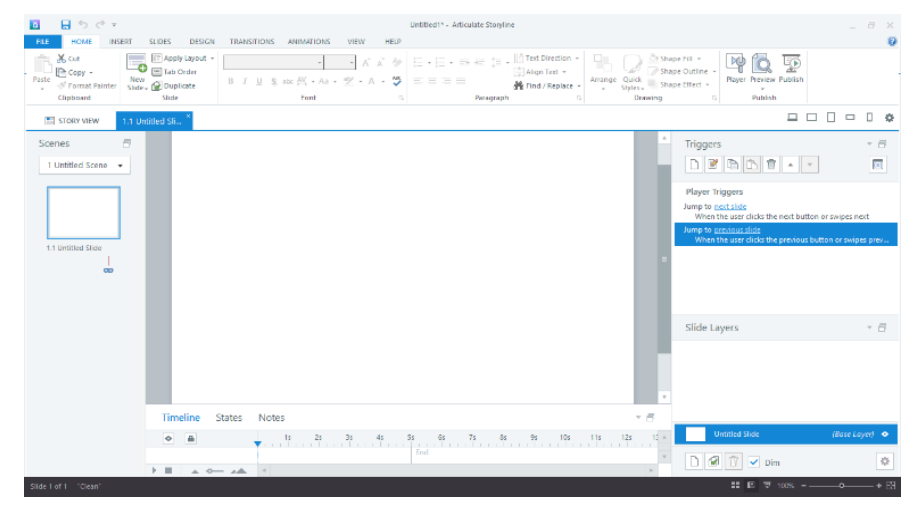

Gambar 3. Lembar Kerja Articulate Storyline

Lembar kerja kosong akan muncul setelah memilih menu new project, kemudian mengatur tampilan slide seperti mengatur slide pada microsoft powerpoint.

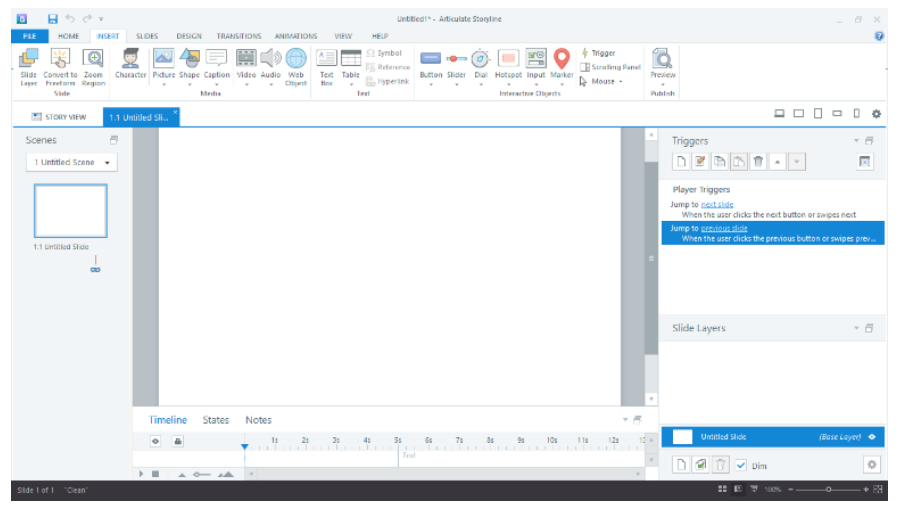

Gambar 4. Icon-Icon yang Menjadi Ciri Khas Articulate Storyline

Pada tab insert terdapat icon-icon berupa karakter yang berguna untuk menampilkan karakter kartun yang diinginkan, button untuk memilih icon tombol yang akan diatur pada trigger sehingga dapat menampilkan jump slide otomatis, dan masih banyak icon khusus lainnya yang terdapat pada group interactive object.

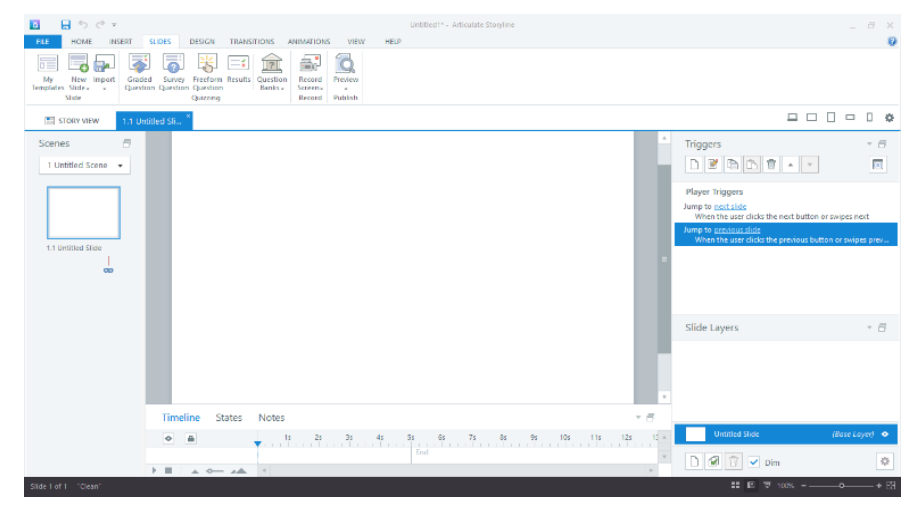

Gambar 5. Pilihan Pengaturan Fitur Kuis Interaktif 
Terdapat fitur pilihan yang dapat dipilih ketika membuat kuis, pilihan-pilihan yang disajikan beragam dan interaktif. Guru dapat mendesain kuis sesuai kebutuhan pada graded question dan dapat menginput jawaban pada bagian result.

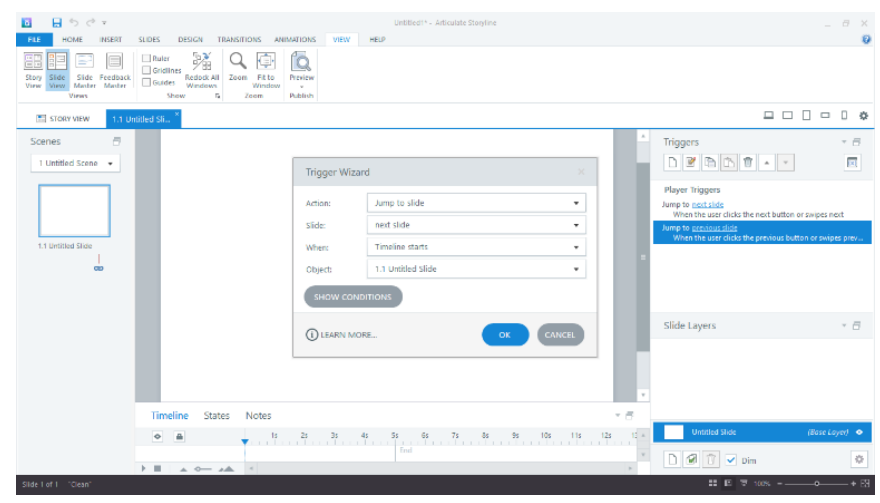

Gambar 6. Fitur Trigger pada Articulate Storyline

Fitur trigger adalah sistem kontrol yang digunakan untuk mengatur suatu objek tertentu pada suatu slide ke slide lainnya. Konsep trigger ini adalah kunci dari kreativitas pembelajaran interaktif pada articulate storyline. Pengaturan trigger ini tidak memerlukan kode-kode khusus, sehingga mudah digunakan. Trigger dapat dipadukan dengan icon button yang terdapat pada icon insert.

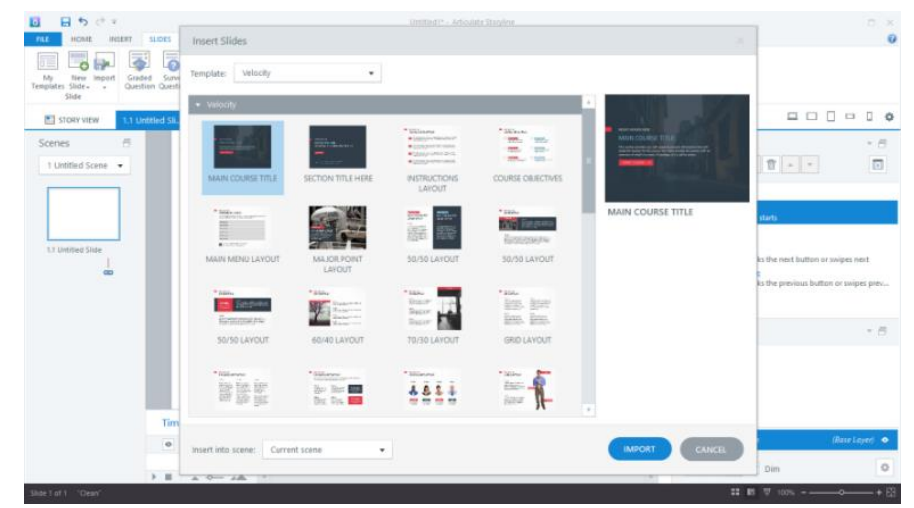

Gambar 7. Template yang Terdapat pada Articulate Storyline

Apabila ingin cepat dalam membuat slide maka dapat memilih template yang telah disediakan. Template ini memudahkan pemula mendesain media pembelajaran interaktif.

\subsubsection{Keunggulan dan Kelemahan Articulate Storyline}

Media pembelajaran interaktif berupa penggunaan software articulate storyline memiliki banyak keunggulan, sehingga tepat digunakan sebagai media pembelajaran untuk meningkatkan interaksi aktivitas dan pemahaman peserta didik. Articulate storyline dapat memberikan kemudahan desain dan pengoperasian ketika pembelajaran, menambah pemahaman peserta didik dengan menyisipkan materi dengan memanfaatkan fitur berupa tulisan, suara, dan video mengenai materi yang akan diajarkan.

Media berbasis internet ini menuntut guru dan peserta didik untuk terampil mengoperasikan alat elektronik sehingga peserta didik maupun guru menjadi terampil dalam memanfaatkan teknologi sebagai media pembelajaran. Articulate storyline juga 
mampu menambah kreativitas guru dalam mendesain media pembelajaran yang komunikatif dan interaktif (Darnawati, Jamiludin, Batia, Irawaty, \& Salim, 2019: 13), serta meningkatkan motivasi dan hasil belajar peserta didik (Jusoh \& Zakaria, 2019; Setyaningsih, Rusijono, \& Wahyudi, 2020). Kelebihan lainnya yang dimiliki articulate storyline adalah fitur desain yang mirip microsoft powerpoint, sehingga mudah digunakan bagi pemula, yang membedakan adalah adanya fitur trigger atau tombol otomatis pada articulate storyline yang dengan mudah diinput tanpa memasukkan kodekode yang rumit. Publikasi hasil desain yang telah dibuat dapat diubah menjadi berbasis website yang terbukti efektif mempermudah guru dan peserta didik dalam mencapai tujuan pembelajaran (Santyasa, Juniantari, \& Santyadiputra, 2020: 1788).

Berdasarkan penelitian sebelumnya yang dilakukan oleh Rohmah \& Bukhori, (2020: 97), software articulate storyline layak digunakan sebagai media pembelajaran karena mendukung proses interaksi timbal balik dengan smart brainware sederhana yang dapat diakses dengan icon-icon, sehingga menunjukkan hasil dari timbal balik tersebut. Hasil publikasi yang dapat dibuka secara daring ataupun luring mempermudah peserta didik dalam mempelajari materi yang telah disediakan. Articulate storyline dapat diunduh dengan mudah melalui website milik Articulate 360 serta output yang beragam, sehingga dapat memudahkan guru untuk memilih output yang sesuai dengan kemampuan masing-masing guru dan peserta didik. Output yang paling mudah adalah dengan mengubahnya ke bentuk website (Rohmah \& Bukhori, 2020: 180). Namun, apabila slide yang didesain sebelumnya melalui software articulate storyline terlalu banyak, maka tidak dapat diubah ke dalam bentuk website, sehingga slide harus dibatasi supaya dapat dengan mudah diakses melalui website oleh peserta didik. Hal tersebut menjadi kelemahan dari articulate storyline (Fatia \& Ariani, 2020).

Kelemahan lainnya terkait akses yakni perangkat tersebut hanya dapat digunakan secara gratis oleh pengguna selama 30 hari sebagai fasilitas free trial, selebihnya dapat diakses secara langganan dengan biaya sesuai jangka waktu yang dibutuhkan. Tentunya hal ini menjadi penghambat bagi guru untuk membuat multimedia interaktif berulang kali (Khusnah, Sulasteri, Suharti, \& Nur, 2020: 65). Hal lain yang juga menjadi kelemahan dari articulate storyline yaitu ketika desain pembelajaran telah dibuat dengan banyak slide kemudian diterbitkan dalam bentuk HTML, maka HTML tersebut tidak dapat berdiri sendiri, artinya memerlukan software lain sebagai alternatif akses. Selain itu, ketika telah diterbitkan, tampilan articulate storyline belum tersedia dalam bentuk full HD. Hal ini dapat memungkinkan tampilan teks dan gambar yang kecil tidak begitu terlihat (Sam, 2021).

\subsection{Pembahasan}

Media pembelajaran interaktif memiliki persyaratan yaitu media mampu menambah motivasi peserta didik, bertujuan memberikan motivasi belajar untuk peserta didik, dan media dapat memberikan rangsangan atau stimulus kepada peserta didik mengenai hal yang baru mereka pelajari (Istiqlal, 2017: 45). Media pembelajaran interaktif juga harus bersifat menarik dan menyenangkan, sehingga membuat peserta didik tertarik dan berinteraksi langsung dengan media tersebut (Yuniati, Purnama, \& Nurgoho, 2017: 26).

Articulate storyline dapat digunakan sebagai software pembantu membuat media pembelajaran yang interaktif kepada peserta didik. Software yang dapat dibuat dengan mengklik button pada output articulate storyline merupakan bentuk interaksi peserta didik dengan media tersebut. Foto, audio, dan video yang ditambahkan ke output 
articulate storyline dapat digunakan sebagai sumber belajar lain bagi peserta didik dan mampu berinteraksi dengan sumber belajar tersebut. Adanya animasi yang menarik juga dapat menambah motivasi belajar dan interaksi peserta didik dengan media pembelajaran. Hasil pengembangan media pembelajaran articulate storyline yang dilakukan oleh Nissa, Toyib, Sutarni, Akip, Kadir, Ahmad, \& Solikin, (2021) dan Octavia, Surjanti, \& Suratman, (2021) menunjukkan bahwa media pembelajaran articulate storyline valid dan efektif digunakan sebagai media pembelajaran. Hal ini juga sesuai dengan penelitian yang telah dilakukan oleh Fatia \& Ariani (2020), Nugroho \& Arrosyad (2021), dan Rohmah \& Bukhori (2020).

Keaktifan peserta didik dalam proses pembelajaran sangat penting dalam penerapan kurikulum 2013, sehingga media pembelajaran interaktif bagi peserta didik Madrasah Ibtidaiyah sangat diperlukan untuk menambah motivasi belajar mereka (Pratama \& Batubara, 2021). Kelebihan yang diberikan oleh articulate storyline dapat bermanfaat bagi peserta didik pada jenjang MI apabila guru sebagai pembuat media mengoptimalkan fungsi dari fitur-fitur software tersebut. Karakteristik peserta didik di MI yang menyukai animasi-animasi yang menarik dan tampilan yang sesuai dengan usia mereka menjadikan mereka akan tertarik dan termotivasi untuk belajar menggunakan articulate storyline (Suhailah, Muttaqin, Suhada, Jamaluddin, \& Paujiah, 2021: 20).

\section{Simpulan}

Articulate storyline adalah perangkat lunak yang memiliki fungsi sebagai pendukung pembelajaran yang yang mirip dengan microsoft powerpoint dengan sistem e-learning. Output dari articulate storyline berupa HTML5, CD, .swf, .exe, dan website. Perangkat ini juga memiliki fitur yang mudah dioperasikan dan didesain dengan menggabungkan visual, audio, dan audio visual sebagai multimedia interaktif, serta dilengkapi dengan icon animasi yang dapat dipilih sesuai dengan karakteristik peserta didik MI. Pemanfaatannya dapat meningkatkan interaksi, motivasi belajar, dan aktivitas belajar peserta didik.

\section{Daftar Pustaka}

Arwanda, P., Irianto, S., \& Andriani, A. (2020). Pengembangan Media Pembelajaran Articulate Storyline Kurikulum 2013 Berbasis Kompetensi Peserta Didik Abad 21 Tema 7 Kelas IV Sekolah Dasar. Al-Madrasah: Jurnal Pendidikan Madrasah Ibtidaiyah, 4(2), 193-204. https://doi.org/10.35931/am.v4i2.331

Bulan, S., \& Wahyudi, W. E. (2021). Pengembangan Media Pembelajaran Al-Qur'an Hadits Terintegrasi Seni melalui Narasi Berbasis Gambar Bercerita Surat Al-Fil untuk Membangun Kemampuan Berpikir Siswa. Journal of Instructional and Development Researches, 1(1), 10-19. https://doi.org/10.53621/jider.v1i1.18

Darnawati, Jamiludin, Batia, L., Irawaty, \& Salim. (2019). Pemberdayaan Guru melalui Pengembangan Multimedia Pembelajaran Interaktif dengan Aplikasi Articulate Storyline. Amal Ilmiah: Jurnal Pengabdian kepada Masyarakat, 1(1), 8-16. https://doi.org/10.36709/amalilmiah.v1i1.8780

Elhamid, T., \& Anufia, B. (2019). Resume: Instrumen Pengumpulan Data. Jurnal Studi Islam, 2(1), 1-20. https://doi.org/10.31227/osf.io/s3kr6

Fatia, I., \& Ariani, Y. (2020). Pengembangan Media Articulate Storyline 3 pada Pembelajaran Faktor dan Kelipatan Suatu Bilangan di Kelas IV Sekolah Dasar. 
Journal of Basic Education Studies, 3(2), 503-511. https://ejurnalunsam.id/ index.php/jbes/article/view/2797

Hadza, C., Sesrita, A., \& Suherman, I. (2020). Development of Learning Media Based on Articulate Storyline. Indonesian Journal of Applied Research (IJAR), 1(2), 80-85. https://doi.org/10.30997/ijar.v1i2.54

Istiqlal, M. (2017). Pengembangan Multimedia Interaktif dalam Pembelajaran Matematika. Jurnal Ilmiah Pendidikan Matematika, 2(1), 43-54. https://doi.org/ 10.26877/jipmat.v2i1.1480

Juhaeni, Safaruddin, Nurhayati, R., \& Tanzila, A. N. (2020). Konsep Dasar Media Pembelajaran. JIEES: Journal of Islamic Education at Elementary School, 1(1), 34-43. https://doi.org/10.47400/jiees.v1i1.11

Jusoh, J. S. Bin, \& Zakaria, A. B. Bin. (2019). Self-Study Preparation via Articulate Storyline/Rise Improves Students' Motivation. 11th Social Sciences Postgraduate International Seminar (SSPIS 2019), 228-235. http://www.soc. usm.my/images/pdf/2019/Proceedings_of_2019_SSPIS.pdf\#page $=238$

Kadir, M., Ningsih, D. A., Hasmiati, \& Qadrianti, L. (2021). Karakteristik Kepemimpinan Madrasah Ibtidiyah. Jurnal Pendidikan Dasar dan Keguruan, 6(1), 14-23. https://doi.org/10.47435/jpdk.v6i1.583

Khusnah, N., Sulasteri, S., Suharti., \& Nur, F. (2020). Pengembangan Media Pembelajaran Jimat Menggunakan Articulate Storyline. Jurnal Analisa, 6(2), 197-208. https://doi.org/10.15575/ja.v6i2.9603

Leztiyani, I. (2021). Optimalisasi Pengguaan Articulate Storyline 3 dalam Pembelajaran Bahasa dan Sastra Indonesia. Jurnal Pendidikan Indonesia, 2(1), 24-35. https://doi.org/10.36418/japendi.v2i1.63

Nissa, A. D. A., Toyib, M., Sutarni, S., Akip, E., Kadir, S., Ahmad, \& Solikin, A. (2021). Development of Learning Media Using Android-Based Articulate Storyline Software for Teaching Algebra in Junior High School. Journal of Physics: Conference Series, 1720(012011), 1-7. https://doi.org/10.1088/17426596/1720/1/012011

Nugroho, F., \& Arrosyad, M. I. (2021). Learning Multimedia Development Using Articulate Storyline for Students. International Journal of Elementary Education, 4(4), 575-579. https://doi.org/10.23887/IJEE.V4I4.27763

Octavia, A. D., Surjanti, J., \& Suratman, B. (2021). Pengembangan Media M-Learning Berbasis Aplikasi Articulate Storyline untuk Meningkatkan Hasil Belajar Peserta Didik Sekolah Menengah Atas. Edukatif: Jurnal Ilmu Pendidikan, 3(5), 23802391. https://doi.org/10.31004/edukatif.v3i5.797

Pratama, A. N., \& Batubara, H. H. (2021). Pengembangan Multimedia Interaktif Berbasis Articulate Storyline Materi Penerapan Nilai-Nilai Pancasila. Bidayatuna: Jurnal Pendidikan Guru Madrasah Ibtidaiyah, 4(2), 159-170. https://doi.org/10.36835/bidayatuna.v4i2.1082

Pratama, R. A. (2018). Media Pembelajaran Berbasis Articulate Storyline 2 pada Materi Menggambar Grafik Fungsi di SMP Patra Dharma 2 Balikpapan. Jurnal Dimensi, 7(1), 19-35. https://doi.org/10.33373/dms.v7i1.1631

Razilu, Z. (2021). Pengembangan Mobile Learning Berbasis Android Menggunakan Articulate Storyline 3 di Sekolah Dasar. DECODE: Jurnal Pendidikan Teknologi Informasi, 1(1), 17-21. https://doi.org/10.51454/decode.v1i1.3

Rianto. (2020). Pembelajaran Interaktif Berbasis Articulate Storyline 3. Indonesian Language Education and Literature, 6(1), 84-92. https://doi.org/10.24235/ileal. 
v6i1.7225

Rohmah, F. N., \& Bukhori, I. (2020). Pengembangan Media Pembelajaran Interaktif Mata Pelajaran Korespondensi Berbasis Android Menggunakan Articulate Storyline 3. Ecoducation: Economic and Education Journal, 2(2), 169-182. http://ejurnal.budiutomomalang.ac.id/index.php/ecoducation/article/download/8 92/523/

Safaruddin, Degeng, I. N. S., Setyosari, P., \& Murtadho, N. (2020). The Effect of PJBL with WBL Media and Cognitive Style on Students' Understanding and ScienceIntegrated Concept Application. Jurnal Pendidikan IPA Indonesia, 9(3), 384395. https://doi.org/10.15294/jpii.v9i3.24628

Sam, N. (2021). Pengembangan Multimedia Pembelajaran pada Mata Pelajaran IPS di SMP Negeri 46 Makassar. Educational Technology, Curriculum, Learning, and Comunication, 1(3), 138-148. https://doi.org/10.26858/jetclc.v1i3.21215

Santyasa, I. W., Juniantari, M., \& Santyadiputra, G. S. (2020). Efektivitas Pelatihan Pembuatan Media Pembelajaran Interaktif Berbasis Articulate Storyline 3 untuk Guru-Guru di SMAN 2 Singaraja. Proceeding Senadimas Undiksha, 1784-1790. https://lppm.undiksha.ac.id/senadimas2020/assets/ProsidingSenadimas2020/file/ 246.pdf

Saski, N. H., \& Sudarwanto, T. (2021). Kelayakan Media Pembelajaran Market Learning Berbasis Digital pada Mata Kuliah Strategi Pemasaran. Jurnal Pendidikan Tata Niaga (JPTN), 9(1), 1118-1124. https://ejournal.unesa.ac.id/ index.php/jptn/article/view/40502

Setyaningsih, S., Rusijono, \& Wahyudi, A. (2020). Pengaruh Penggunaan Media Pembelajaran Interaktif Berbasis Articulate Storyline terhadap Motivasi Belajar dan Hasil Belajar Siswa pada Materi Kerajaan Hindu Budha di Indonesia. Didaktis: Jurnal Pendidikan dan Ilmu Pengetahuan, 20(2), 144-156. https://doi. org/10.30651/didaktis.v20i2.4772

Suhailah, F., Muttaqin, M., Suhada, I., Jamaluddin, D., \& Paujiah, E. (2021). Articulate Storyline: Sebuah Pengembangan Media Pembelajaran Interaktif pada Materi Sel. Pedagonal: Jurnal Ilmiah Pendidikan, 5(1), 19-25. https://doi.org/10.33 751/pedagonal.v5i1.3208

Supriana, I. W., \& Sukmana, I. W. K. T. (2018). Peningkatan dan Pengembangan Pengajaran Berbasis Teknologi bagi Guru-Guru di SMK Pariwisata Margarana. Jurnal Widya Laksana, 7(1), 47-54. https://doi.org/10.23887/jwl.v7i1.12564

Tanjung, M. R., \& Parsika, T. F. (2017). Pengembangan Aplikasi Multimedia Pengenalan dan Pembelajaran Origami dengan Pendekatan ADDIE. Seminar Nasional Informatika, 128-133. http://e-journal.potensi-utama.ac.id/ojs/index. php/SNIf/article/view/226

Trianingsih, R. (2016). Pengantar Praktik Mendidik Anak Usia Sekolah Dasar. Al Ibtida: Jurnal Pendidikan Guru MI, 3(2), 197-211. https://doi.org/10.24235/ al.ibtida.snj.v3i2.880

Wibowo, T. (2021). Konseptualisasi Integrasi Psikologi dan Islam (Psikologi Islam) dalam Pembelajaran di Madrasah Ibtidaiyah. Jurnal Pendidikan Dasar, 6(1), 113. https://doi.org/10.26877/jipmat.v2i1.1480

Yuniati, N., Purnama, B. E., \& Nurgoho, G. K. (2017). Pembuatan Media Pembelajaran Interaktif Ilmu Pengetahuan Alam pada Sekolah Dasar Negeri Kroyo 1 Sragen. Jurnal Speed-Sentra Penelitian Engineering dan Edukasi, 3(4), 25-29. https://doi.org/10.3112/speed.v3i4.866 